\title{
ESTRATÉGIAS DE ENSINO PELA ÓTICA DOS ESTUDANTES: REFLEXÕES SOBRE A APRENDIZAGEM
}

FONSECA, Sônia*

MAGINA, Sandra**

\begin{abstract}
RESUMO
O presente estudo tem por objetivo investigar as práticas pedagógicas do professor universitário pela ótica dos estudantes. Para tanto, desenvolvemos um estudo com a participação de 103 estudantes advindos de três cursos pertencentes a duas áreas distintas: exatas (licenciatura em Matemática - 25 estudantes - e Engenharia da Produção - 36 estudantes) e social (Administração - 42 estudantes). A metodologia utilizada apoiou-se nos paradigmas da pesquisa descritiva que envolveu a aplicação coletiva (com os estudantes respondendo individualmente) de um questionário e uma entrevista com características de semidirigida. Esta foi aplicada a aproximadamente $14 \%$ dos participantes, entre uma semana e 15 dias após o questionário. Os resultados da pesquisa indicam que o estudante, independente da área em que seu curso se insere e mesmo que de maneira intuitiva, consegue ter clareza entre as boas e as más práticas pedagógicas, elencando-as e avaliando-as com clareza e discernimento. $\mathrm{O}$ estudo concluiu que o professor universitário, independente do seu nível de titulação, carece de uma formação que contemple disciplinas didáticas para realizar a contento seu papel de formador.
\end{abstract}

Palavras-chave: Prática Pedagógica. Aprendizagem. Docência. Estudo Diagnóstico. Ensino Superior.

\footnotetext{
* Mestre em Administração pela FGV/SP e Doutora em Educação pela PUC/SP. Professora do curso de Administração e membro do colegiado do Mestrado Profissional em Educação da Universidade Estadual de Santa Cruz (UESC), Ilhéus, BA. Membro do grupo de pesquisa RePARe (CNPq). E-mail: soniafonseca19@gmail.com

** Mestre em Psicologia pela UFPE e Doutora em Educação Matemática pela Universidade de Londres, pós-doutora pela Universidade de Lisboa. Professora do curso de Matemática e membro dos colegiados dos mestrados em Educação e Educação Matemática da Universidade Estadual de Santa Cruz - UESC; líder do grupo de pesquisa RePARe (CNPq). E-mail: sandramagina@gmail.com.
} 


\title{
e-Curriculum
}

Programa de Pós-Graduação em Educação: Currículo

TEACHING STRATEGIES FROM THE STUDENTS’ POINT OF VIEW: REFLECTIONS

ABOUT LEARNING

FONSECA, Sônia*

MAGINA, Sandra**

\begin{abstract}
The present study aims to investigate the pedagogical practices of the university teacher, from the students point of view of the. For that purpose, we developed a study envolving 103 students coming from three different courses, which come from two distinct areas: exact (Mathematics degree - 25 students - and Production Engineering - 36 students) and social (Administration - 42 students). The methodology used was based on the paradigms of the descriptive research and consisted of: (a) a questionnaire applied collectively (with the students answering individually) and (b) an interview, with semi-directed characteristics. This was applied to approximately $14 \%$ out of the all participants, carried out between one week and 15 days after the questionnaire. The results of the research indicate that students, regardless of the area in which their course is inserted and even in an intuitive way, can be clear about good pedagogical practices, listing them and evaluating them with clarity and discernment. The study concludes that the university teacher, regardless of his level of qualification, needs to be best prepared, mainly in didactic subjects, in order to be able to perform this fuction well.
\end{abstract}

Keyword: Pedagogical Practices; Learning; Teaching; Diagnostic Study. Under Graduation.

\footnotetext{
* Master in Managment by FGV/SP e PhD in Education by PUC/SP. Lecture in Management course and member of Professional Education Master from the State University of Santa Cruz (UESC), Ilheus, BA. Member of the research group RePARe (CNPq). E-mail: soniafonseca19@gmail.com

** Master in Psychology by UFPE e PhD in Mathematics Education by University of London. Lecture of Mathematics course and member of bothEdutation and Mathematics Education from State University of Santa Cruz - UESC; lider of the research group RePARe (CNPq). E-mail: sandramagina@gmail.com.
} 


\title{
e-Curriculum
}

Programa de Pós-Graduação em Educaçãa: Currículo

\section{ESTRATEGIAS DE ENSEÑANZA EN LA ÓPTICA DE LOS ESTUDIANTES: \\ REFLEXIONES SOBRE EL APRENDIZAJE}

\section{FONSECA, Sônia}

MAGINA, Sandra**

\begin{abstract}
RESUMEN
El presente estudio tiene por objetivo investigar las prácticas pedagógicas del profesor universitario bajo la óptica de los estudiantes. Para ello desarrollamos un estudio con la participación de 103 estudiantes provenientes de tres cursos pertenecientes a dos áreas distintas: exactas (licenciatura en Matemáticas 25 estudiantes - e Ingeniería de la Producción - 36 estudiantes) y social (Administración - 42 estudiantes). La metodología utilizada se apoyó en los paradigmas de la investigación descriptiva y constó de: (a) una aplicación colectiva (con los estudiantes respondiendo individualmente) de un cuestionario y (b) una entrevista con características semi-dirigidas. Se aplicó a aproximadamente el 14\% de los participantes, entre una semana y 15 días después del cuestionario. Los resultados de la investigación indican que el estudiante, independientemente del área en que su curso se inserta e incluso de manera intuitiva, logra tener claridad sobre las buenas prácticas pedagógicas, enumerándolas y evaluándolas con claridad y discernimiento. El estudio concluye que el profesor universitario, independiente de su nivel de titulación, carece de una formación que contemple disciplinas didácticas, para realizar a satisfacción su papel de formador.
\end{abstract}

Palabras clave: Práctica pedagógica. Aprendizaje. Enseñaza. Estudio diagnóstico. Enseñanza superior.

\footnotetext{
* Doutora em Educação pela PUC/SP e Mestre em Administração pela FGV/SP. Professora do curso de Administração e membro do colegiado do Mestrado Profissional em Educação da Universidade Estadual de Santa Cruz (UESC), Ilheus, BA. Membro do grupo de pesquisa RePARe (CNPq). E-mail: soniafonseca19@gmail.com

** Pós-doutora pela Universidade de Lisboa, PhD pela London University e Mestre em Psicologia pela UFPE. Professora do curso de Matemática e membro dos colegiados dos mestrados em Educação e em Educação Matemática da Universidade Estadual de Santa Cruz - UESC; lider do grupo de pesquisa RePARe (CNPq). E-mail: sandramagina@gmail.com.
} 


\section{e-Curriculum}

Programa de Pós-Graduação em Educação: Currículo

\section{INTRODUÇÃO}

Os desafios de uma sociedade em frenéticas mudanças, em todas as áreas do conhecimento, exigem do sistema educacional respostas eficientes e rápidas que possam atender às demandas da informação e do conhecimento, embora saibamos que a informação e o conhecimento, foram, são e serão partes importantes em qualquer momento da história e de suas transformações. Para tanto, o professor, com a sua formação, é parte fundamental do atendimento aos desafios que as mudanças requerem.

A profissão docente é permeada de especificidades e com distintos significados, inclusive de funções, pois se espera do profissional, além da formação qualitativa de seus estudantes, também a formação política. Espera-se mais de um professor do que de qualquer outra profissão. Entretanto, a responsabilidade pela formação continuada, especificamente do professor universitário, é basicamente 'dele'. As universidades públicas não têm em seus estatutos ou Planos de Desenvolvimento Institucional (PDI) um planejamento que priorize a formação pedagógica de seu professor. Anualmente, as avaliações da Comissão Própria de Avaliação (CPA) apontam as diversas deficiências pedagógicas, mas pouco, ou nada, tem sido feito institucionalmente.

Assim, com a preocupação de que esse cenário se perpetue, o presente estudo pretende promover uma reflexão sobre as estratégias pedagógicas utilizadas por professores nos cursos de graduação em Licenciatura em Matemática, Administração e Engenharia da Produção, desde o olhar dos estudantes desses cursos. O estudo foi realizado em uma universidade pública do sul da Bahia.

O objetivo do estudo foi investigar as práticas pedagógicas do professor universitário pela ótica dos estudantes. Ou, mais especificamente, investigar as estratégias de ensino que despertam maior e/ou menor motivação do estudante pela disciplina. Nessa direção, buscamos analisar algumas práticas pedagógicas utilizadas pelos professores dos cursos citados e sua eficiência em despertar interesse nos estudantes. 


\section{e-Curriculum}

Programa de Pós-Graduação em Educação: Currículo

Assim, buscamos responder as seguintes questões de pesquisa: Quais estratégias de ensino despertam a motivação do estudante na aprendizagem de uma disciplina e como ele percebe a participação do professor nisso?

De partida, é importante elucidar o que entendemos por motivação e por aprendizagem. Iniciamos afirmando que esses dois termos estão fortemente relacionados.

A palavra "motivação" vem do latim, 'motivu' e significa aquilo que move, referindo-se ao ato ou efeito de motivar. Ela é intrínseca, vem de dentro, embora emerja de estímulos externos, advindos do ambiente. É um conjunto de fatores psicológicos (conscientes ou inconscientes) de ordem fisiológica, intelectual ou afetiva, os quais agem entre si e determinam a conduta de um indivíduo.".

Já a aprendizagem se relaciona com os termos estudo, preparação, aquisição, conhecimento. Do ponto de vista psicopedagógico, é possível entender a aprendizagem como um processo que gera mudança de comportamento obtida a partir da experiência da pessoa. Ela é construída por meio de vários fatores, tais como emocionais, relacionais, cognitivo e ambientais.

Assumimos, junto com Ausubel (1980), que para haver a aprendizagem é preciso que haja uma disposição para tal. E entendemos que esta vem dos fatores intrínsecos à motivação. Assim, a motivação pode ser considerada a mola mestra da aprendizagem, envolvendo tanto aspectos emocionais como cognitivos. Por essa ótica, Ausubel (2000, p. 200) explica que os fatores motivacionais

[...] influenciam diretamente as próprias condições que determinam a interação entre o novo material de aprendizagem e as ideias relevantes existentes na estrutura cognitiva. [...]. Estimulam e apressam este processo durante a aprendizagem, ao aumentarem o esforço, a atenção e a prontidão imediata para a aprendizagem. Assim, elevam a força de dissociabilidade, de forma catalítica e não-específica (AUSUBEL, 2000, p. 200).

Com relação à motivação, fazemos um paralelo entre a gestão organizacional de maneira geral (indústrias, escolas, lojas, etc.) e a gestão da sala de aula, tomando o professor como o gestor organizacional, como o responsável pela maestria da sinfonia de seus conteúdos. Ou seja, 


\section{e-Curriculum}

Programa de Pós-Graduação em Educação: Currículo

um agente principal para gerar esse elemento motivador em seus estudantes. A motivação será melhor discutida a seguir.

\section{O DESPERTAR DA MOTIVAÇÃO PARA APRENDER}

A crescente importância das organizações na sociedade contemporânea desperta o aprofundamento e a sistematização de conhecimentos que garantam a sua continuação e adaptação aos contextos das mudanças de paradigmas que a própria sociedade impõe. Para tanto, as organizações precisam apoiar-se em teorias que procurem conciliar a natureza humana, suas crenças, realizações e valores, aos interesses da comunidade. Uma das teorias importantes para esse fim é a motivacional. Afinal, se não estamos motivados para aprender, ensinar, trabalhar, viajar, etc., não conseguiremos avançar em nenhuma das áreas da capacidade humana.

Um dos estudiosos que mais trouxe contribuição sobre o estudo da motivação foi Herzberg (1968). Suas inquietações a respeito do assunto surgiram nos campos de batalha em que esteve lutando durante a Segunda Guerra Mundial. Para ele, uma parte da motivação de um sujeito se dá dentro do próprio ambiente de trabalho, denominado como fator extrínseco, que interfere positivamente ou negativamente na motivação. A outra parte é o fator intrínseco ao sujeito. Ele depende de várias influências, tais como família e escola, além do próprio esforço individual para adquiri-lo. Herzberg explica a necessidade de fatores como reconhecimento, responsabilidade, honestidade e estímulo a desafios para manter a motivação adquirida.

Herzberg toma o meio social, a organização, como a fonte motivadora do indivíduo. Toma o indivíduo como meio e transforma os seus desejos na necessidade da organização. A organização através dos fatores motivacionais manipula o indivíduo, motiva-o. Reduz a auto-realização à realização da tarefa. $\mathrm{O}$ indivíduo se motiva no trabalho pelos fatores que se relacionam diretamente com o trabalho (HERZBERG, 1968, p. 126).

Assim, Herzberg (1968) entende que a motivação das pessoas para atingir objetivos decorre da satisfação, ou insatisfação, dos dois fatores (extrínsecos e intrínsecos). No caso do trabalhador significaria, por exemplo, um bom salário, política de valorização do trabalhador pela empresa, reconhecimento etc.; enquanto para o estudante seria a valorização de suas dúvidas e opiniões sobre o conteúdo ensinado, a boa nota, o reconhecimento da atividade realizada etc. 


\section{e-Curriculum}

Programa de Pós-Graduação em Educação: Currículo

Em dois de seus textos, Mc Gregor (1960; 1994) complementa o entendimento sobre motivação, explicando, por meio das Teorias X e Y, que a motivação das pessoas depende do padrão de comportamento promovido pelo líder (gestor). $\mathrm{O}$ autor argumenta que no padrão de comportamento da "Teoria X", o trabalhador tem aversão ao trabalho e, portanto, o líder precisa ser controlador, ameaçador e punitivo para que esse atinja os objetivos da organização. O líder entende que o resultado da motivação se dá apenas pelas recompensas externas e pelo medo da punição.

Já no padrão de comportamento da "Teoria Y", o líder vê o trabalhador como sendo capaz, como alguém que gosta de trabalhar e de desafios. Assim, o padrão de comportamento do líder, para a motivação, é o que proporciona condições para que as pessoas se desenvolvam, reconheçam-se e descubram por si próprias seus potenciais.

De pronto, podemos nos perguntar: e o que o ambiente de organizações tem em comum com a sala de aula? Quase tudo. O professor é o líder, é o gestor da sala de aula, que poderá sensibilizar os estudantes à motivação tornando-os estimulados à aquisição de mais conhecimentos. Enquanto líder, ele pode ser autocrático (ou autoritário), liberal (laissez-faire) ou democrático.

Esclarecemos, baseadas em especialistas da área (MAXWELL, 2002; MINICUCCI, 1995) que um líder autocrático (ou autoritário) é aquele que decide sozinho, fixando ele próprio as diretrizes a seguir, sem que haja qualquer participação do grupo que ele lidera; ele decide que tarefa realizar e como ela deve ser realizada. Trata-se, portanto, de uma figura dominadora e sectária. Já o líder liberal (ou laissez-faire) tem características passivas, pouco se manifesta ou interfere nas decisões do grupo, permitindo, muitas vezes, posturas individuais simultâneas, denotando a falta de firmeza e de decisão. Por fim, o líder democrático se caracteriza por permitir e estimular a participação de seus liderados nas decisões da condução das tarefas. Assim, o grupo discute as diretrizes a seguir sob o aconselhamento do líder. Este decidirá como dar-se-á a realização da tarefa apenas após ter escutado e debatido com seus liderados.

\section{O PAPEL DO PROFESSOR NA APRENDIZAGEM DO ESTUDANTE}

Sônia FONSECA, Sandra MAGINA Estratégias de ensino pela ótica dos estudantes: reflexões sobre a aprendizagem. 


\section{e-Curriculum}

Programa de Pós-Graduação em Educação: Currículo

Iniciamos esta seção trazendo uma metáfora proposta por Fonseca (2007) em que o professor, em seu papel de líder autocrático, assume, simultaneamente, três funções pertencentes ao judiciário. Ele pode ser o advogado de defesa (aquele que define a linha de conhecimento a ser adquirido pelo estudante, gerando ele próprio a prova para esse estudante); o promotor (aquele que aponta o quanto o estudante aprendeu) e o juiz (aquele que julga e sentencia a nota que o estudante merece tirar). Nesse cenário, cabe ao estudante receber sua 'sentença' com pouco ou nenhum direito a defesa.

Se considerarmos o professor pela ótica de um líder democrático, a nota passa a ser consequência direta do conhecimento adquirido; o padrão de comportamento do estudante é o de se tornar autônomo, superando desafios e se tornando protagonista de seu próprio desenvolvimento. Mas para assumir tal posição, é necessário que o professor tenha recebido uma formação de líder educador, tendo, evidentemente, avançado para além da apropriação dos conteúdos específicos da disciplina que leciona.

Podemos dividir os professores dos cursos analisados neste estudo (Licenciatura em Matemática, Engenharia da Produção e Administração) em dois perfis: aqueles que tiveram formação em disciplinas na área pedagógica e os que não tiveram. A maioria desses profissionais, mestres e doutores, é formada por professores bem preparados tecnicamente em suas áreas profissionais. Eles são: bons contabilistas, administradores, advogados, estatísticos, matemáticos, engenheiros, mas pedagogicamente fazem a gestão da sala de aula por tentativa e erro, ou por feeling. São profissionais-professores e não professores-profissionais; aprenderam a exercer o papel de professor no decorrer do exercício de sala de aula. São até bem intencionados, porém não têm background pedagógico e deixam de ser facilitadores da aprendizagem de seus estudantes.

Nessa perspectiva, a formação técnica do professor não é condição única e suficiente que possibilite, em sua atividade docente, a indução do estudante ao sucesso em seu processo de aprendizagem. Como agente decisório desse processo, é preciso mais; é necessário considerar o princípio de que uma profissão é uma realidade viva, coletiva e proativa. Como afirma Tardif (2008, p.70) acerca da formação para o profissionalismo docente: 


\section{e-Curriculum}

[...] uma formação que desenvolve "a especificidade do saber ensinar", que insiste na importância dos "saberes para ensinar" ao lado da maestria do "saber ensinar". Esta afirmação reconhece a especificidade de um "profissionalismo docente" como "trabalho interativo" em situação pedagógica, contextualizada, finalizada. O ensino "prática relacional finalizada pela aprendizagem," é uma profissão complexa, que não pode ser definida na sua complexidade em termos de tarefas, de métodos ou de técnicas planificadas a priori. A aplicação das competências docentes faz-se em situações interativas, contextualizadas e particulares (TARDIF, 2008, p.70).

Chamamos atenção para a frase escrita por Tardif (2008, p.70) de que a profissão docente é “[...] uma profissão complexa, que não pode ser definida na sua complexidade em termos de tarefas, de métodos ou de técnicas planificadas a priori”. De fato, concordamos com o autor e entendemos que a formação pedagógica do professor, que contribui para a transformação de seu estudante, é intencional. Isto significa que se tornar professor exige não apenas um preparo inicial, mas também uma formação a partir da prática docente construída pela experiência do dia a dia. Por isso a formação do professor precisa ser continuada ao longo da vida profissional.

A forma como as Instituições do Ensino Superior (IES), sejam elas públicas ou privadas, contratam seus professores colabora com a desarticulação curricular e a consequente eficiência da aprendizagem. O professor é contratado para um componente curricular (disciplina) específico, limitando-se a ministrá-lo de forma desconectada com o conjunto dos outros componentes curriculares do curso. Isso costuma dificultar a aprendizagem do estudante porque o conteúdo vem descontextualizado e perde o significado. O estudante de Administração, por exemplo, não entende porque tem que estudar a disciplina de Sociologia. Assim, o saber docente não pode estar desalinhado da dimensão do ensino, nem da dimensão profissional. É preciso que o corpo docente tenha uma visão do perfil do egresso que o curso deseja formar.

As crenças e os valores dos professores também têm forte influência sobre o ensino e interferem em suas práticas de sala de aula (NÓVOA, 2009). Nóvoa costuma afirmar em muitas de suas palestras que: “[...] na educação não é possível separar a dimensão profissionalidade da dimensão da pessoalidade e isso implica em um compromisso pessoal, de valores, do ponto de vista da profissão".

Concordamos com Nóvoa e entendemos que para que os professores sejam "atores e construtores de conhecimento" precisam ser preparados para tal, o que significa receber uma 


\section{e-Curriculum}

Programa de Pós-Graduação em Educação: Currículo

formação pedagógica que lhes permita desempenhar tal função. Será que a universidade, em seus cursos de licenciatura e/ou pós-graduação stricto sensu, tem preparado tal profissional? Entendemos que permeando toda essa discussão está a compreensão de que a falta da formação pedagógica docente traz prejuízos ao processo de aprendizagem. E um dos aspectos da formação docente é a interação professor-estudante. Assim, a metodologia do professor na gestão da sala de aula compromete a motivação do estudante e, consequentemente, seus resultados no sucesso da aprendizagem, conforme entende Masetto (2003, p. 48):

A interação professor-aluno, tanto individualmente quanto com o grupo, se destaca como fundamental no processo de aprendizagem e se manifesta na atitude de mediação pedagógica por parte do professor, na atitude de parceria e co-responsabilidade pelo processo de aprendizagem entre aluno e professor e na aceitação de uma relação entre adultos assumida por professor e aluno (MASETTO, 2003, p. 48).

Compreender esse contexto defendido por Masetto dependerá da disposição docente em manter um clima na sala de aula apropriado para tal. O desenvolvimento de um clima apropriado à aprendizagem depende da dimensão pessoal do docente, de maneira que o seu comportamento é determinado como resultado das necessidades do estudante e independentemente do seu papel institucional. Outra dimensão que também interfere no clima da sala de aula é a dimensão social, que descreve como os estudantes se organizam dentro da instituição e como suas expectativas se desenvolvem no contexto vivenciado em sala de aula. $\mathrm{O}$ clima motivador marca positivamente as expectativas dos estudantes, interferindo na sua relação com o docente e com a disciplina.

Construir contextos de aprendizagem produtivos e motivadores é um processo complexo. Não é tarefa fácil criar atividades de aprendizagem que desafiem os 'mais capazes' e, ao mesmo tempo, despertem o interesse dos 'menos capazes'. As estratégias utilizadas pelos docentes para motivar os estudantes não vêm em manual de práticas pedagógicas que traga receitas que sirvam para todos os grupos de estudantes. A sensibilidade e a experiência docente falarão mais alto para fazer as adaptações de acordo com os grupos. Segundo Fonseca (2007), algumas estratégias podem ajudar na motivação e no desenvolvimento de atitudes e habilidades, como: relacionamento interpessoal, responsabilidade, liderança, criatividade, atitude ética, atitude 


\section{$e$-Curriculum}

Programa de Pós-Graduação em Educação: Currículo

empreendedora, aprendizado contínuo e solidariedade. Essas são desenvolvidas, intencionalmente, por meio do domínio das estratégias de ensino para motivar o estudante.

Desse modo, Fonseca (2007) desenvolveu uma matriz de estratégias de ensino mostrando como cada uma delas tende a ser eficiente e refletir na motivação, atitudes e habilidades dos estudantes que foram sujeitos de seu estudo. A Tabela 1 apresenta tal matriz.

\begin{tabular}{|c|c|c|}
\hline $\begin{array}{c}\text { Técnica de } \\
\text { Ensino utilizadas } \\
\text { pelo docente }\end{array}$ & Descrição da Técnica & $\begin{array}{l}\text { Resultado das atitudes e habilidades observadas } \\
\text { pelo estudante }\end{array}$ \\
\hline $\begin{array}{l}\text { 1) Aula } \\
\text { expositiva } \\
\text { (Preleção) }\end{array}$ & $\begin{array}{l}\text { Verbalização unilateral do docente sobre os temas } \\
\text { do programa da disciplina. }\end{array}$ & $\begin{array}{l}\text { Atitude passiva; aprende a ouvir e anotar, atitude } \\
\text { submissa; desperta a reprodução nas avaliações } \\
\text { de desempenho. Não motiva. }\end{array}$ \\
\hline $\begin{array}{l}\text { 2) Estudo de caso } \\
\text { com resolução } \\
\text { de problemas }\end{array}$ & $\begin{array}{l}\text { Escolha do caso (ou da literatura sugerida pelos } \\
\text { estudantes). Relaciona-se o caso com a teoria, } \\
\text { faz-se o diagnóstico, escolhe-se uma solução. } \\
\text { Mantém-se contato com a situação real. }\end{array}$ & $\begin{array}{l}\text { Desenvolve o raciocínio lógico criativo; aprende } \\
\text { a fazer diagnóstico; dialogar com o grupo; } \\
\text { respeitar as diferenças; desenvolve a } \\
\text { solidariedade. É considerada motivadora. }\end{array}$ \\
\hline $\begin{array}{l}\text { 3) Ensino com } \\
\text { debates }\end{array}$ & $\begin{array}{l}\text { O docente escolhe um tema, dá prazo para a } \\
\text { preparação dos grupos e há a exposição das ideias. }\end{array}$ & $\begin{array}{l}\text { Desenvolve habilidade de expressar-se em } \\
\text { público; poder de síntese; poder de argumentação } \\
\text { com contraponto de ideias. Respeito. }\end{array}$ \\
\hline $\begin{array}{l}\text { 4) Estudo em } \\
\text { grupo }\end{array}$ & $\begin{array}{l}\text { Logo no início das aulas, o docente deixa que os } \\
\text { grupos sejam formados livremente. Após a } \\
\text { apresentação do trabalho, o docente dissolve o } \\
\text { grupo e forma os próximos por sua escolha }{ }^{(1)}\end{array}$ & $\begin{array}{l}\text { Desenvolve a habilidade de relação interpessoal; } \\
\text { de flexibilidade; ampliação dos conhecimentos e } \\
\text { troca de experiências; desenvolve a atitude de } \\
\text { consenso. }\end{array}$ \\
\hline $\begin{array}{l}\text { 5) Dinâmica de } \\
\text { grupo }\end{array}$ & $\begin{array}{l}\text { Prática de técnicas que procuram desenvolver o } \\
\text { gerenciamento e orientação de equipes na } \\
\text { resolução de problemas }\end{array}$ & $\begin{array}{l}\text { Aumenta a relação interpessoal; aprende a } \\
\text { respeitar opiniões diversas; prática da flexibilidade } \\
\text { e consenso. }\end{array}$ \\
\hline $\begin{array}{l}\text { 6) Visitas } \\
\text { técnicas }\end{array}$ & $\begin{array}{l}\text { Visitas a empresas consideradas modelo; museus; } \\
\text { exposições. }\end{array}$ & $\begin{array}{l}\text { Vivencia os casos teóricos; aumenta a harmonia } \\
\text { entre o grupo; diminui a timidez; desperta o } \\
\text { prazer pelo conhecimento. }\end{array}$ \\
\hline $\begin{array}{l}\text { 7) Jogos } \\
\text { específicos }^{(2)}\end{array}$ & $\begin{array}{l}\text { São utilizados com finalidades específicas de } \\
\text { acordo com a disciplina. }\end{array}$ & $\begin{array}{l}\text { Descontrai; aguça o raciocínio na busca de } \\
\text { estratégias; ajuda a criar laços entre os colegas; } \\
\text { casa alegria e euforia, motiva. }\end{array}$ \\
\hline
\end{tabular}

Tabela 1: Técnicas de ensino relatadas pelos docentes e os resultados na formação de habilidades e atitudes Fonte: Fonseca, 2007, p. 207.

\footnotetext{
${ }^{1}$ É relatado pelos estudantes que essa técnica quebra paradigmas, evita formação de 'panelas' aumenta, a relação interpessoal com os outros grupos, cria flexibilidade nas relações no sentido de perceber que nem sempre trabalhamos ou convivemos com quem temos afinidades. Via de regra, há muita reclamação por parte dos estudantes, mas depois há o reconhecimento, em muitos casos, que descobriram os mais 'novos amigos de infância'

2 Jogos físicos como: Quadrados Quebrados, Tangram, Triângulo Mosaico, Xadrez, Ações Exame, Máster etc.
} 


\section{$e$-Curriculum}

Programa de Pós-Graduação em Educação: Currículo

Note que apenas a primeira técnica de ensino (entendida aqui como estratégia) colocada na Tabela 1, elaborada por Fonseca (2007), põe o estudante em posição passiva e, consequentemente, desmotivado para a aprendizagem. Todas as outras atribuem ao estudante um papel proativo, dentro de ambiente descontraído e/ou harmônico e/ou solidário, privilegiando a intercomunicação entre professor-estudante e entre estudante-estudante.

\section{METODOLOGIA}

O presente estudo apoiou-se nos paradigmas da pesquisa descritiva. Trata-se de um estudo que teve por objetivo conhecer e interpretar determinados fenômenos ligados à realidade sem nela interferir para modificá-la (RUDIO, 2001). A coleta de dados se realizou por meio da aplicação de um questionário (Figura 1) composto por oito questões estruturadas, oferecendo respostas de múltiplas escolhas. As quatro primeiras questões voltavam-se a identificar grupos de disciplinas consideradas como de influência positiva para o estudante e sua relação com as práticas pedagógicas do professor. Já as outras quatro, buscavam identificar o grupo de disciplinas que tinha marcado negativamente suas formações, observando se esses participantes as relacionavam com os docentes desse grupo de disciplinas e suas práticas. Assim, as questões investigavam se o aluno identificava a relação entre a prática pedagógica do professor e se tais práticas interferem no seu interesse pela disciplina. Para melhor compreender as respostas, entrevistamos entre 13 e $16 \%$ dos estudantes de cada curso, em um período que variou entre uma semana e 15 dias após a aplicação do questionário. Foram entrevistados ao todo 15 estudantes (14,6\% da amostra total).

Participaram desta pesquisa 103 estudantes oriundos de uma universidade pública estadual do sul da Bahia. Os estudantes encontravam-se distribuídos em três grupos, a saber:

GRUPO 1: composto por 25 estudantes que estavam no $8^{\circ}$ período do curso de Licenciatura em Matemática. Quatro deles foram entrevistados. Esses estudantes já atuavam como professores do Ensino Fundamental e estavam em formação pelo Plano Nacional de Formação de Professores da Educação Básica (PARFOR). As disciplinas desse curso dividiam-se em exatas (relacionadas à 


\section{e-Curriculum}

Programa de Pós-Graduação em Educaçãa: Currículo

Matemática), humanistas (voltadas para a Educação) e as técnicas (envolvendo a relação entre os saberes teóricos e os estágios). Este grupo receberá a sigla de GLM.

GRUPO 2: composto por 36 alunos do $8^{\circ}$ semestre do curso de Engenharia da Produção. Cinco deles foram entrevistados. Este curso, que pertence à área das Engenharias, tinha como característica ter uma formação que abrangia as disciplinas da área de Exatas (relacionadas à Matemática), as da área de Humanas (relacionadas à Administração e afins) e as de áreas técnicas (envolvendo a relação entre os saberes teóricos e os estágios). Chamaremos este grupo pela sigla GEP.

GRUPO 3: composto por 42 alunos do $8^{\circ}$ semestre do curso de Administração. Seis foram entrevistados. O curso tinha por característica oferecer disciplinas da área de Ciências Sociais, da área de Exatas e disciplinas técnicas (envolvendo a relação entre os saberes teóricos e os estágios). A sigla que utilizaremos para este grupo é GAD.

Sobre as disciplinas cursadas, em comum, por esses estudantes podemos dizer que:

a) todos tiveram, pelo menos, três disciplinas de Matemática e/ou Estatística;

b) todos já tinham cursado, pelo menos, uma disciplina de estágio supervisionado, duas de Humanas (e/ou Social, do tipo: Educação, recursos Humanos, Gestão, Psicologia, Sociologia), duas de Exatas (Matemática e afins) e uma disciplina técnica (relacionadas à formação profissional) em cada um dos cursos.

O questionário foi aplicado coletivamente, com os estudantes respondendo individualmente. Foi informado a eles que o instrumento não continha qualquer dado que permitisse a identificação do estudante que o respondeu, a menos que ele aceitasse ser entrevistado depois. Nesse caso, pediu-se ao estudante que colocasse seu nome na parte superior do questionário. Foi solicitado que todos os estudantes escrevessem a abreviatura do seu curso, e posteriormente todos os questionários foram numerados para facilitar os procedimentos posteriores de análise. A seguir apresentamos o questionário na íntegra. 


\section{e-Curriculum}

Programa de Pós-Graduação em Educação: Currículo

1. QUAL DOS GRUPO DE DISCIPLINAS ABAIXO MAIS LHE MARCOU POSITIVAMENTE DURANTE SUA FORMAÇ̃̃O? a) GRUPo DAS DisciplinAS da ÁREA DE EXATAS (MATEMÁtiCAS E AFins) ( )

b) Grupo das Disciplinas da ÁREa de humanas ou sociais (EduCAÇão, Sociologia, Psicologia, ETC) ( )

c) GRUPO DAS DISCIPLINAS TÉCNICAS (RELACIONADAS À FORMAÇÃO PROFISSIONAL) ( )

2. SUA ESCOLHA NA QUESTÃo ANTERIOR TEVE RELAÇ̃̃o DIRETA COM O PROFESSOR DA DiSCIPLINA? SIM ( ) NÃo ( )

3. SE SIM, QUAL OU QUAIS DOS ITENS ABAIXO CARACTERIZAVA BEM ESSE PROFESSOR?

a) DEMONSTRA CONHECIMENTO DO CONTEÚDO ( )

b) MOSTRA CONHECIMENTO ALÉM DO CONTEÚDO E BUSCA SEMPRE INOVAR SUA PRÁTICA PEDAGÓGICA ( )

c) ESTIMULA O ALUNO PAA FAZER PERGUNTAS E A EMITIR OPINIÕES ( )

d) É RESPONSÁVEL, CHEGA NO HORÁRIO, DÁ RETORNO ÀS DEMANDAS DOS ALUNOS ( )

e) POUCO INTERESSE/TEMPO PARA REEXPLICAR AO ALUNO CONTEÚDOS APRESENTADOS NA AULA ( )

f) TRATA O ALUNO COM DISTÂNCIA DEIXANDO DELIMITADA A HIERÁRQUICA ENTRE ELES ( )

g) DEIXA CLARO QUE A APRENDIZAGEM É RESPONSABILIDADE DO ALUNO E O ENSINO DELE ( )

h) PERECE ATRIBUIR NOTA MAIOR A QUEM CONCORDA CONSIGO E/OU FAZ POUCAS PERGUNTAS ( )

4. QUAIS DAS PRÁTICAS PEDAGÓGICAS ABAIXO ESSE PROFESSOR COSTUMA USAR E QUE VOCÊ CONSIDERA TER FACILITADO SUA APRENDIZAGEM?

a) Aula Expositiva (PREleÇão) ( )

b) ESTUdo DE CASO COM RESOLUÇÃO DE PROBLEMAS E/OU RESOLUÇÃO DE PROBLEMAS ( )

c) CONSTRUČ̃̃ DE CONCEITOS POR MEIO DE DEBATES ( )

d) ESTUDO EM GRUPO ( )

e) DINÂMICAS DE GRUPO ( )

f) Jogos ( )

g) Outros ( )

5. QUAL DOS GRUPO DE DISCIPLINAS ABAIXO MAIS LHE MARCOU NEGATIV AM ENTE DURANTE SUA FORMAÇÃO? a) GRUPO DAS DISCIPLINAS DA ÁREA DE EXATAS (MATEMÁTICAS E AFINS) ( )

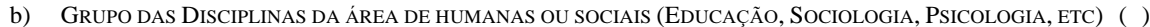

c) GRUPO DAS DisCIPLINAS TÉCNICAS (RELACIONADAS À FORMAÇÃO PROFISSIONAL) ( )

6. SuA ESCOLHA NA QUESTÃo ANTERIOR TEVE RELAÇão DiRETA COM O PROFESSOR? Sim ( ) Não ()

7. SE SIM, QUAL OU QUAIS DOS ITENS ABAIXO CARACTERIZAVA BEM ESSE PROFESSOR?

a) DEMONSTRA CONHECIMENTO DO CONTEÚDO ( )

b) MOSTRA CONHECIMENTO ALÉM DO CONTEÚDO E BUSCA SEMPRE INOVAR SUA PRÁTICA PEDAGÓGICA ( )

c) ESTIMULA O ALUNO PAA FAZER PERGUNTAS E A EMITIR OPINIÕES ( )

d) É RESPONSÁVEL, CHEGA NO HORÁRIO, DÁ RETORNO ÀS DEMANDAS DOS ALUNOS ( )

e) POUCO INTERESSE/TEMPO PARA REEXPLICAR AO ALUNO CONTEÚDOS APRESENTADOS NA AULA ( )

f) TRATA O ALUNO COM DISTÂNCIA DEIXANDO DELIMITADA A HIERÁRQUICA ENTRE ELES ( )

g) DEIXA CLARO QUE A APRENDIZAGEM É RESPONSABILIDADE DO ALUNO E O ENSINO DELE ( )

h) PERECE ATRIBUIR NOTA MAIOR A QUEM CONCORDA CONSIGO E/OU FAZ POUCAS PERGUNTAS ( )

8. CONSIDERANDO O QUE VOCÊ ENTENDE POR BOM PROFESSOR, ATRIBUA UMA NOTA PARA CADA UMA DAS CARACTERÍSTICAS ABAIXO, ENTENDENDO QUE 5 É A PONTUAÇÃO MÁXIMA E ZERO A MAIS BAIXA.

a) TER DOMÍNIO DOS CONTEÚDOS ENSINADOS ()

b) SER PROFESSOR COM ALTO NÍVEL DE TITULAÇÃo (

c) UTILIZAR PRÁTICAS PEDAGÓGICAS QUE FACILITEM A COMPREENSÃO DO ALUNO SOBRE OS CONTEÚDOS ( )

d) SER PONTUAL E CUMPRIR COM RIGOR SUAS ATIVIDADES PLANEJADAS EM SEU PROGRAMA （ ）

e) SeR RESILIENTE, COMPREENSIVO E EDUCADO ( )

f) TRATAR OS ALUNOS COM A DistÂNCIA NECESSÁRIA PARA TER CONTROLE SOBRE SEUS COMPORTAMENTOS （ ）

g) ESTIMULAR O ALUNO A FAZER PERGUNTAS E PONDERAÇÕES, INCLUSIVE DISCORDAR DO PROFESSOR （ ）

h) PARTIR SEMPRE DA DEFINIÇÃO, SEGUIDO POR UM EXEMPLO QUE TAMBÉM ESTEJA NO LIVRO ADOTADO (

Figura 1: O questionário utilizado pelo estudo para a recolha dos dados

Fonte: Elaborado pelas autoras especificamente para o estudo em questão em 2015.

Após a aplicação nos três grupos, o que se deu em dois dias consecutivos, foram separados aqueles questionários em que os estudantes se mostraram receptivos para participar das entrevistas (63 estudantes aceitaram ser entrevistados). Essas foram realizadas individualmente nos 15 dias que sucederam a aplicação do questionário. Foram entrevistados 15 estudantes. Os critérios de escolha desses estudantes foram: (a) disponibilidade para um encontro fora do horário de aula, e (b) a coincidência de horários livres entre as pesquisadoras e o estudante na semana em 


\section{e-Curriculum}

Programa de Pós-Graduação em Educaçãa: Currículo

que as entrevistas seriam realizadas. Quando atingimos os 15 estudantes que planejávamos entrevistar (quatro do GLM, cinco do GAD e seis do GEP), encerramos essa etapa da pesquisa.

De posse dos dados, procedemos com as análises dos resultados obtidos, as quais se encontram na seção a seguir.

\section{RESULTADOS}

Iniciaremos a análise procedendo com uma comparação das respostas dadas pelos estudantes às questões que são antagônicas. Assim, os primeiros resultados que apresentaremos dizem respeito às questões 1 e 5 . A questão 1 trata do grupo de disciplinas que mais marcou positivamente os estudantes ao longo do curso; enquanto que a questão 5 refere-se ao grupo de disciplinas que mais os marcou negativamente ao longo do curso. É interessante perceber que tanto na questão 1 como na 5, os três grupos de disciplinas são os mesmos.

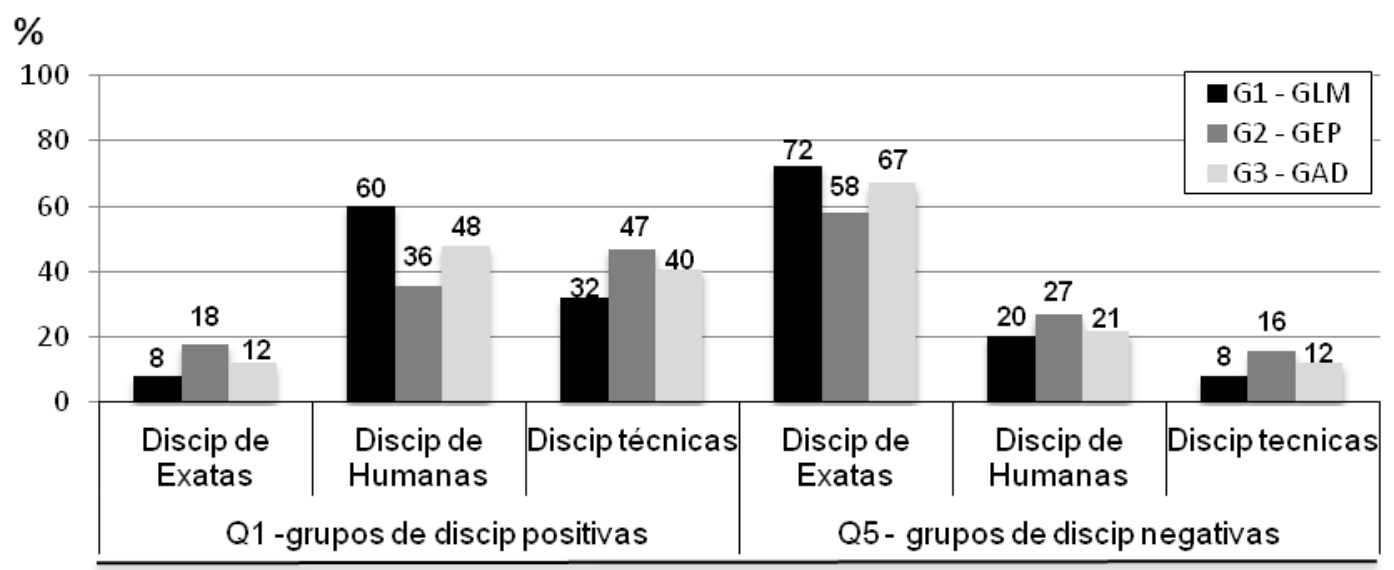

Gráfico 1: Comparação das avaliações dos estudantes para o grupo de disciplinas que os marcou positivamente e o grupo que marcou negativamente

Discip Exatas = grupo das disciplinas pertencentes a área de Exatas;

Discip de Humanas = grupo das disciplinas pertencentes a área Humanas e/ou Sociais;

Discip técnicas $=$ grupo das disciplinas pertencentes a área profissional do Curso.

Q1 = questão 1; Q5 = questão 5 .

O Gráfico 1 apresenta dados em que o grupo de disciplinas escolhido como o que mais marcou positivamente os estudantes dos três grupos variou entre a área de Humanas e as técnicas. Na verdade, há uma unanimidade entre os estudantes dos três cursos nas questões 1 e 5, que foi 


\section{$e$-Curriculum}

Programa de Pós-Graduação em Educação: Currículo

com relação ao grupo de disciplinas de Exatas. Este grupo foi o que mais marcou negativamente, e o grupo menos escolhido por influenciado positivamente os estudantes.

Inicialmente, tal resultado nos chamou a atenção principalmente no que se refere aos estudantes do GEP que, embora tenha um forte viés administrativo, é um curso de Engenharia. Surpreendeu-nos sobremaneira encontrar uma rejeição maior ainda no grupo GLM, pois trata-se de futuros professores de Matemática do Ensino Básico. Ao serem entrevistados sobre o porquê dessa rejeição, encontramos respostas como as que se seguem:

Os professores dessas disciplinas (exatas) parece que dão aula para eles mesmos, nem olham pra gente. eu tive que cursar a disciplina de cálculo I (diferencial e integral) três vezes e não foi só eu não. passei na terceira, mas continuo sem entender ela, e o professor parece que fica contente de reprovar a maioria da classe [...] a gente procura ele e não adianta nada [....] a disciplina de álgebra linear eu não sei pra que fiz e pra que me serve. as disciplinas de física i e ii poderia ter sido apenas a i e os professores poderiam pelos menos tentar dizer o que elas têm a ver com nosso curso [...] a gente fica solto, eles não dizem nada [...] eles ensinam por ensinar, só pensando no conteúdo [...] como se a gente fosse ser matemático $\left(\mathrm{GEP}_{(\mathrm{aluno} 9)}\right)$

O professor de Geometria reprovou a turma toda, 100\%! Será que nenhum de nós aprendeu nada? A gente ficou desesperado porque ia atrapalhar muito o curso. Aí uma professora, que não é da matemática pura, ofereceu essa disciplina de novo em horário de verão e foi outra coisa, foi ótima, teve muitas atividades, pensamos na nossa sala de aula, em como ensinar geometria pros estudantes e também pra que ensinar geometria [...] a maioria dos professores das disciplinas de pura (conteúdo específico de matemática) eles nem olhavam pra gente [...] A gente aprendeu como não ensinar, [....] viu como é ruim ter um professor que não nos respeitam, que nem enxergam a gente [...] Então, a gente aprendeu um pouco de Matemática, mas aprendeu mais em como ensinar matemática pelo contrário. $\left(\mathrm{GLM}_{(\text {aluno 6) }}\right)$

A gente não sabe pra que aprender as coisas do Cálculo. Pra que vai nos servir saber calcular uma integral? quando vamos usar isso na nossa profissão? mesmo a função, pra que? [...] os professores das disciplinas de matemática só fazem ensinar matemática, não fazem relação. Aí a gente estuda integral e no semestre seguinte estuda juros. Como é isso? (rsrsrs) qual o sentido? É preciso saber integral para entender juros compostos? eles não dizem nada, nem a gente. A disciplina de Estatística é a mesma coisa, o professor não traz nenhum exemplo da Administração [...] ele disse que tava lá pra ensinar a estatística, que ele foi contratado para isso. Aí é danado porque fica uma calculeira só, um monte de fórmula que a gente nem entende pra que e quando usar [...] é só resolva, resolva, resolva. $\left(\mathrm{GAD}_{\text {(aluno 3) }}\right)$ 


\section{e-Curriculum}

Programa de Pós-Graduação em Educaçãa: Currículo

Notamos, nas falas dos três estudantes, que há pouca relação e comunicação entre os professores das disciplinas de Exatas e os estudantes; os conteúdos são ensinados sem relacionálos com a profissão para a qual eles estão sendo formados. Tal distanciamento parece ser um forte componente de insatisfação dos estudantes com as disciplinas de Exatas e isso vale para os três cursos. Notamos, também, nessas falas, que o professor parece exercer papel importante nessa satisfação ou insatisfação. Tal resultado nos faz refletir sobre a lacuna do líder democrático e motivador na sala de aula (McGREGOR, 1960).

A seguir, os resultados referentes às questões 2 e 6, apresentados no Gráfico 2, apoiam nossa conjectura.

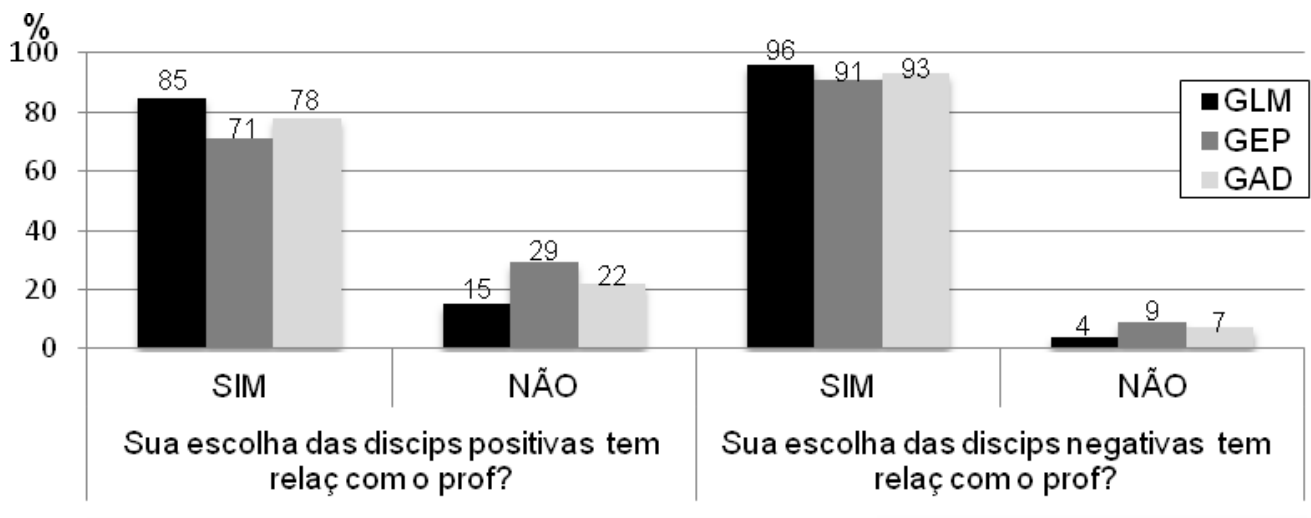

Gráfico 2: Comparação das avaliações dos estudantes sobre a relação direta do professor sobre disciplinas positivas e negativas

Os resultados apresentados no Gráfico 2 não deixam dúvida sobre a importância do papel do professor no envolvimento dos estudantes na disciplina, como salientam, Nóvoa (2002) e Masetto (2003). Sabemos que há vários fatores que interferem na relação do estudante com a disciplina, mas os dados mostram que o professor é certamente um deles. Os dados apontam, ainda, que essa consciência da interferência do professor ficou muito mais reconhecida pelos estudantes quando se tratava de uma disciplina que os marcou negativamente - mais de $90 \%$ dos estudantes de todos os grupos marcaram "SIM" na questão 6 (sobre a relação entre professor e disciplina que marcou negativamente os alunos). 


\section{e-Curriculum}

Programa de Pós-Graduação em Educação: Currículo

É interessante notar que entre os estudantes de Engenharia da Produção, embora tenham seguido a mesma tendência dos estudantes dos dois outros cursos, essa relação foi um pouco menos forte, principalmente no que tange à questão 2 (sobre a relação entre professor e disciplina que marcou positivamente os alunos). Quando entrevistados, a principal justificava oferecida dos estudantes do GEP e do GAD, que responderam "NÃO" à questão 2, foi de que a disciplina era tão interessante que o professor não conseguia intervir negativamente, como se a disciplina tivesse vida própria, como ilustrado na resposta do estudante 11, do GEP:

A disciplina é legal, faz a gente pensar bastante e tem muitos desafios. Aí não dá pro professor atrapalhar não (risos). No curso tem muito professor doutor e isso é bom, os caras sabem muito $\left(\mathrm{GEP}_{(\mathrm{aluno} 11)}\right)$

Esse mesmo estudante marcou "SIM" na questão 6 e explicou:

Muito professor não tem nenhuma didática. Eles sabem o conteúdo mas não sabem ensinar, ficam falando baixo, só olham pro quadro e explicam do mesmo jeito, não adianta perguntar [...] Tem muito prô (professor) que fica só mandando fórmulas, a gente não entende direito, aí vem a prova, ele manda um monte de problemas diferentes e aí a gente se dá mal [...] $\left(\mathrm{GEP}_{(\text {aluno } 11)}\right)$

Essa aparente incoerência do estudante 11 pode ser explicada porque apenas no eventual fracasso se busca culpados externos a nós. Tardif (2008) pondera que na situação em que o estudante vai bem numa disciplina, ele costuma gostar dela, como se ela, por si só, fosse suficiente para gerar esse gostar; não presta suficiente atenção ao papel do professor como mediador desse conhecimento, como aquele que escolhe os desafios e as atividades propostas ao longo da disciplina. Já se a disciplina mostrou-se difícil, então o papel do professor, como mediador e facilitador desse conhecimento, parece ganhar importância. Esse comportamento foi notado especialmente na fala dos estudantes do grupo GEP.

Já os estudantes do GLM, os quais já atuavam como professores do Ensino Básico e viviam, simultaneamente, o papel de estudantes (do curso de Licenciatura em Matemática) e de 


\section{e-Curriculum}

Programa de Pós-Graduação em Educação: Currículo

professor (de escola pública), demonstravam claramente perceber o importante papel do professor no processo de aprendizagem dos seus estudantes, como mostra o extrato a seguir:

É claro que o professor tem tudo a ver com o gosto pela disciplina e também pela nossa aprendizagem. A gente teve uma disciplina chamada de Psicologia da Educação. Ela fez a gente olhar para o ensino de outro jeito. A gente elaborou atividades de matemática pensando na teoria de aprendizagem que tava por trás da atividade. E depois a gente aplicou essa atividade nos nossos alunos e ainda analizou as estrategias que eles usaram e que levaram ao acerto ou ao erro. No final a gente apresentou num seminário e foi super legal a discursão. Eu nunca tinha pensado que o erro podia interessar, ser uma coisa boa (rsrsrs). Essa disciplina fez a gente entender a importância do professor no processo de aprendizagem do aluno e isso nós sentimos dos dois lados: enquanto aluno do curso e também como professor na escola. Por isso gente não faltava essa aula, todo mundo adorava. $\left(\operatorname{GLM}_{(\text {aluno 2) }}\right)$

Esse discurso do estudante 2 do GLM é uma clara tomada de consciência sobre a importância do professor no processo de aprendizagem do estudante. Tratou-se de um trecho em que identificamos a importância da motivação (HERZBERG, 1968; AUSUBEL, 2003), do líder Y (McGREGOR, 1960) e do professor enquanto mediador e construtor do conhecimento (TARDIF, 2008; NÓVOA, 2002; MASETTO, 2003).

$\mathrm{Na}$ sequência, analisamos as questões 3 e 7, que fazem as mesmas perguntas e que se apresenta na Figura 2 a seguir, referentes às características do professor. Lembrando que essas questões têm relações diretas com as questões imediatamente anteriores a elas (2 e 6).

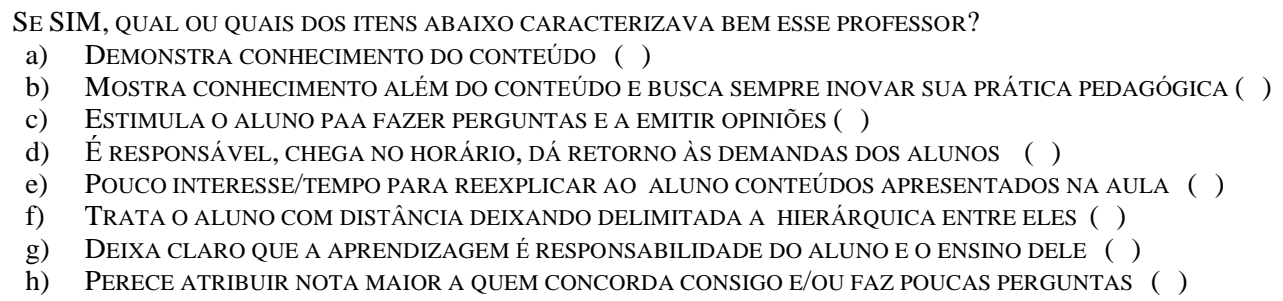

Figura 2: texto referente às questões 3 e 7 do questionário utilizado pelo estudo para a recolha dos dados Fonte: Elaborado pelas autoras especificamente para o estudo em questão em 2015. 


\section{$e$-Curriculum}

Programa de Pós-Graduação em Educação: Currículo

As Tabelas 2 e 3, a seguir, apresentam as opiniões de cada um dos grupos (em porcentagem) sobre a importância de cada uma das características listadas nas perguntas 3 e 7 .

\begin{tabular}{c|cccccccc|l}
\hline Item & $\mathbf{a}$ & $\mathbf{b}$ & $\mathbf{c}$ & $\mathbf{d}$ & $\mathbf{e}$ & $\mathbf{f}$ & $\mathrm{g}$ & $\begin{array}{c}\mathrm{h} \\
\text { Gm \% }\end{array}$ & $\begin{array}{c}\text { Total } \\
\text { Em \% }\end{array}$ \\
$\begin{array}{c}\text { Gm \% } \\
\text { Em \% }\end{array}$ & Em \% & Em \% & Em \% & Em \% & \\
$\begin{array}{c}\text { GLM } \\
(\mathrm{n}=25)\end{array}$ & 4 & 68 & 21 & 7 & - & - & - & - & 100 \\
$\begin{array}{c}\text { GEP } \\
(\mathrm{n}=36)\end{array}$ & 15 & 60 & 5 & 17 & - & - & 3 & - & 100 \\
$\begin{array}{c}\text { GAD } \\
(\mathrm{n}=42)\end{array}$ & 8 & 62 & 17 & 13 & - & - & 1 & - & 100 \\
\hline
\end{tabular}

Tabela 2: A opinião dos estudantes dos três cursos pesquisados sobre atitude de um professor cuja disciplina marca positivamente a formação do estudante (questão 3).

Fonte: as autoras

\begin{tabular}{|c|c|c|c|c|c|c|c|c|c|}
\hline Item & $\begin{array}{c}\mathbf{a} \\
\mathbf{E m} \%\end{array}$ & $\begin{array}{c}\text { b } \\
\text { Em \% }\end{array}$ & $\begin{array}{c}\text { C } \\
\text { Em \% }\end{array}$ & $\begin{array}{c}\text { d } \\
\text { Em \% }\end{array}$ & $\begin{array}{c}\mathrm{e} \\
\mathrm{Em} \%\end{array}$ & $\begin{array}{c}\mathrm{f} \\
\text { Em \% }\end{array}$ & $\underset{\mathbf{E m} \%}{\mathrm{~g}}$ & $\stackrel{\mathrm{h}}{\mathbf{E m} \%}$ & $\begin{array}{l}\text { Total } \\
\text { Em \% }\end{array}$ \\
\hline $\begin{array}{c}\text { GLM } \\
(\mathrm{n}=25)\end{array}$ & & & & & 61 & 10 & 11 & 18 & 100 \\
\hline $\begin{array}{c}\text { GEP } \\
(\mathrm{n}=36)\end{array}$ & & & & & 57 & 3 & 2 & 38 & 100 \\
\hline $\begin{array}{c}\text { GAD } \\
(\mathrm{n}=42)\end{array}$ & & & & & 58 & 12 & 9 & 21 & 100 \\
\hline
\end{tabular}

Tabela 3: A opinião dos estudantes dos três cursos pesquisados sobre atitude de um professor cuja disciplina marca negativamente a formação do estudante (questão 7)

Fonte: as autoras

A Tabela 2 mostra que as características de um bom professor estão basicamente nos quatro primeiros itens da lista (mais de 95\% em todos os cursos) e, dentre esses, o item "b" (Mostra conhecimento além do conteúdo e busca sempre inovar sua prática pedagógica) foi, sobremaneira, aquele mais reconhecido pelos estudantes de todos os cursos. De fato, essa prática parece ser uma boa estratégia para gerar a motivação para aprender os conteúdos de uma disciplina, pois, além de oferecer inovação nas aulas, permite que os estudantes possam discutir com o professor pontos do entorno da disciplina. 


\section{e-Curriculum}

Programa de Pós-Graduação em Educação: Currículo

Notamos, ainda, nos dados da Tabela 2, um certo conservadorismo nas respostas do grupo GEP, quando 32\% (quase 1/3) dos estudantes desse grupo considerou os itens "a" ou "d" (Demonstra conhecimento do conteúdo; ou É responsável, chega no horário, dá retorno às demandas dos alunos, respectivamente) como suficiente para caracterizar um bom professor. Ou seja, para esse grupo, quando a disciplina foi vista como positiva, o professor parece, no mínimo, invisível ou desimportante no seu processo de aprendizagem. Esse grupo também pouco valorou o docente que abre espaço para dúvidas e opiniões dos estudantes. por essa ótica, podemos conjecturar que um estudante formado com essa visão de ensino, se amanhã optar por ser professor, muito provavelmente será um "líder X" na sala de aula (McGREGOR, 1960).

As opiniões dos outros dois grupos (GLM e GAD) foram muito próximas, escolhendo sobremaneira os itens "b" e "c" (Mostra conhecimento além do conteúdo e busca sempre inovar sua prática pedagógica; e Estimula o aluno para fazer perguntas e a emitir opiniões, respectivamente), sendo que as escolhas do GLM nesses itens foram ainda enfáticas que a do GAD (89\% do GLM e 79\% do GAD). Tais itens referenciam que um bom professor precisa ir além do conhecimento básico, valorizando o docente que estimula ações proativas de seus estudantes.

A Tabela 3 funcionou como um contraponto da 2, isto é, enquanto na Tabela 2 mais de 95\% das respostas de todos os três grupos foram nos quatro primeiros itens; na Tabela 3, 100\% das escolhas dos estudantes foram nos quatro últimos itens. E mais, a maioria dos estudantes dos três grupos marcou o item "e" (Pouco interesse/tempo para reexplicar ao aluno conteúdos apresentados na aula) como aquele que mais caracterizava um mal professor. Esse item apresenta um professor relapso, descompromissado com a aprendizagem de seu aluno e isso, fica claro, nenhum aluno aceita.

Além disso, os estudantes dos três grupos também consideraram como a segunda pior característica de um professor aquele que atribui nota maior ao estudante que concorda com suas opiniões e/ou que é passivo (item " $h$ ”). É importante informar que enquanto os estudantes do GEP destacavam como muito ruim o professor que atribuía melhores notas aos estudantes que concordam com eles, "puxa-sacos" na opinião de todos os cinco estudantes entrevistados desse

Sônia FONSECA, Sandra MAGINA 


\section{$e$-Curriculum}

Programa de Pós-Graduação em Educação: Currículo

grupo, os estudantes dos outros dois grupos achavam péssimo o professor atribuir maiores notas

para aqueles que faziam poucas perguntas, como mostram os extratos de protocolos a seguir.

É que tem professor com muita conversa que não tem nada a ver com o conteúdo... parece uma coisa de "achismo" sabe? e então eles falam muito deles, dos cursos que eles fazem, dos títulos que têm. aí tem alguns alunos que ficam concordando, dando força para esse papo. Pronto: esses alunos vão se dar bem. Eu não gosto disso. E tem muita gente na turma que também não gosta. Acho errado ganhar nota só porque "puxou o saco" do professor. A gente tá ali para aprender, pra perguntar, pra saber os porquês das coisas, entender os conteúdos e não bajular professor para passar na disciplina. $\left(\mathrm{GEP}_{\text {(aluno 13) }}\right)$

Tem muito professor cheio dos títulos que chega na aula, mal cumprimenta a gente e vai logo escrevendo na lousa, parece que a gente nem tá na sala. Aí se alguém começa a fazer pergunta o cara não gosta não e quem perguntou fica marcado. Teve um professor que explicava pra ele mesmo aí um amigo meu fez pergunta e dançou, toda vez que ele abria a boca o professor tirava onda com ele ... aí ele se calou, claro. Precisava passar. A gente ficava pianinho na aula dele e depois se danava estudando, perguntando a um e a outro como fazia (...) Tem muito professor desse tipo no curso, que não quer que a gente pergunte... vai fazer o que, né? a gente precisa terminar (o curso). Com eles eu aprendi como não ensinar; que temos que aprender como dar aula e não só saber os conteúdos. $\left(\mathrm{GLM}_{(\mathrm{aluno} \mathrm{17})}\right)$

Tem alguns professores (cita nome de dois) que são doutores e se acham: ficam fazendo discurso em vez de dar aula; é para só ele falar. Ai quando a gente pergunta porque não ta entendendo ele repete tudo que já disse. Se a gente não entendeu como ele disse, o que adianta repetir? Esse tipo de professor não gosta que a gente fique perguntando não, parece que ofende a ele. Eles se acham, se a gente pergunta é porque é burro, inteligente é quem fica calado, copia tudo e repete igualzinho na prova. Pra que tanto título se nem sabe ensinar o que aprendeu, né? $\left(\mathrm{GAD}_{\text {(aluno 21) }}\right)$

O perfil dos professores referidos pelos estudantes 13, 17 e 21assemelha-se ao do "líder X” (McGREGOR, 1994), buscando pouco ou nenhum fator de motivação que desencadeie o processo de aprendizagem (AUSUBEL, 2003). Não se identifica aqui nenhuma ação do professor que estimule a reflexão e a crítica dos estudantes na direção da apropriação dos conteúdos. Tanto o professor que não produz diálogo produtivo quanto o diálogo excessivo alheio ao conteúdo da disciplina foram muito mal vistos pelos estudantes. 


\section{$e$-Curriculum}

Programa de Pós-Graduação em Educação: Currículo

Os três estudantes também deixam clara a importância de uma formação para a docência (MASETTO 2003; NÓVOA, 2002).

Em resumo, as respostas dos estudantes sobre as atitudes do professor cujas disciplinas os marcaram positiva e negativamente deixaram explícito que as que despertavam maior interesse nos alunos e os marcaram positivamente são aquelas em que os professores demonstravam interesse pelo aprendizado do aluno e tinham conduta ética. Já as que traziam marcas negativas vinham acompanhadas de professor pouco ético e/ou sem compromisso com o processo de aprendizagem de seus estudantes. Salientamos que titulação do professor parece ser percebida como um fator um tanto negativo para os estudantes.

Por fim, foi perguntado na questão 8:

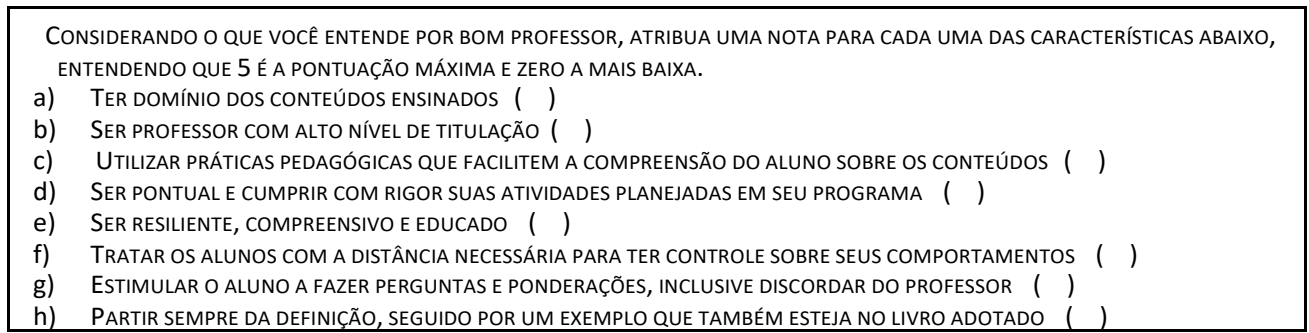

A seguir, os resultados obtidos para esta questão estão expostos na Tabela 4:

\begin{tabular}{l|llllll}
\hline $\begin{array}{l}\text { Pontuação } \\
\text { Características do professor }\end{array}$ & $\mathbf{5}$ & $\mathbf{4}$ & $\mathbf{3}$ & $\mathbf{2}$ & $\mathbf{1}$ & $\mathbf{0}$ \\
\hline a) Ter domínio dos conteúdos ensinados & 100 & -- & -- & -- & -- & -- \\
b) Ser professor com alto nível de titulação & 6 & 11 & 30 & 25 & 19 & 9 \\
c) Utilizar práticas pedagógicas que facilitem a compreensão [....] & 91 & 9 & -- & -- & -- & -- \\
d) Ser pontual e cumprir com rigor suas atividades planejadas [....] & 34 & 8 & 7 & 9 & 30 & 12 \\
e) Ser resiliente, compreensivo e educado & 14 & 19 & 22 & 20 & 19 & 6 \\
f) Tratar os alunos com a distância necessária para ter controle [...] & -- & -- & -- & 16 & 28 & 56 \\
g) Estimular os alunos a fazer perguntas e ponderações [....] & 73 & 7 & 20 & -- & -- & -- \\
h) Partir sempre da definição, seguido por exemplo [...] & -- & -- & -- & 5 & 19 & 76 \\
\hline
\end{tabular}

Tabela 4: A opinião dos estudantes dos três Cursos pesquisados, em porcentagem, sobre as características de um professor (questão 8).

Fonte: as autoras

De acordo com os resultados apresentados na Tabela 4, podemos identificar três grandes grupos: o grupo em que as características do professor foram bem avaliadas, obtendo 100\% das respostas entre 5 e 3 (itens "a", “c" e "g", nesta ordem); o grupo em que as avaliações dos 


\section{e-Curriculum}

Programa de Pós-Graduação em Educação: Currículo

estudantes, em porcentagens, se distribuíram entre 5 e 0 (itens "b", "d" e "e"); e o grupo em que as características comportamentais do professor foram mal avaliadas (itens "f" e "h", cujas avaliações ficaram entre 0 e 2). Mas, o que podemos interpretar de tais avaliações?

Para esses estudantes, são características de bom professor ter o domínio do conteúdo que ensina e para tanto utilizar-se de estratégias pedagógicas que facilitem a compreensão de seus estudantes:

Professor bom é aquele que se preocupa com nossa aprendizagem [...] não adianta só saber, ou ser doutor, pós-doutor, tem que saber ensinar. Quer dizer, o saber é algo muito necessário, mas não suficiente. A gente viu como é importante conhecer estratégias de ensino nas disciplinas de didática do curso. $\left(\mathrm{GLM}_{(\mathrm{aluno} 2)}\right)$

É super legal quando o 'pro' traz jogos pra aula, ou quando discutimos 'cases', faz toda a diferença, porque aula precisa ser dinâmica. É que tem professor que a gente vê que sabe muito, mas não sabe passar esse conhecimento, tem outros que a aula fica chata mesmo porque ele não tem didática. $\left(\mathrm{GAD}_{(\mathrm{aluno12})}\right)$

Os estudantes ainda pontuaram a importância de o professor saber estimular os estudantes a questionar e ponderar sobre o conteúdo em aula.

O professor devia ficar contente quando a gente faz perguntas, ele devia cutucar a gente para fazer isso, porque isso mostra que estamos interessados, aprendendo. $\left(\mathrm{GAD}_{(\text {aluno15) }}\right)$

Por fim, não houve valorização da titulação do professor. A maioria da nota atribuída pelos estudantes a esse item ficou entre 2 e 3 . Os que mais apontaram tal característica como positiva (notas 4 e 5) foram os estudantes do GEP, mas mesmo assim, essa valorização vinha junto com a valorização do saber didático e, ainda, da experiência de mercado, como explicou o estudante 11 desse grupo:

No curso tem alguns professores que são doutores e isso é bom pra gente porque os caras sabem muito. Mas era bom que também tivesse professores que já atuaram no mercado pra poder contar pra gente como as coisas funcionam. A gente aqui dentro não sabe muito disso, do mercado... o professor tem que saber, quanto mais ele sabe melhor, mas tem uns as aulas são chatinhas, cansativas.... tem que saber também ensinar, ne? $\left(\mathrm{GEP}_{(\mathrm{auno11})}\right)$ 


\section{e-Curriculum}

Programa de Pós-Graduação em Educaçãa: Currículo

Os estudantes mostraram-se divididos quanto às características burocráticas do ensino (pontualidade e cumprimento à risca do inicialmente planejado) e, também, da postura mais afável do professor. Em entrevista, alguns deles deixaram clara a preocupação de que a compreensão excessiva e muita polidez tornaria o professor frágil perante a turma, incapaz de garantir o clima propício para a aprendizagem (posição de dois dos estudantes do GAD e quatro do GEP); já outros achavam importante que o professor fosse uma pessoa afável, delicada, que não ironizasse a dúvida e mesmo o não conhecimento do aluno (posição de três dos quatro estudantes do GLM). Esse item foi assim interpretado pelos estudantes tanto do ponto de vista positivo quanto negativo, deixando claro que as óticas eram distintas, uma vez que as experiências desses estudantes com seus professores, igualmente, eram distintas.

Por fim, a partir da análise das respostas dos estudantes ao questionário e, ainda, no âmbito das entrevistas realizadas com parte deles, ficou evidente que as posturas conservadoras e pouco empáticas do professor, mantendo-se distante dos estudantes, foram mal avaliadas. A titulação do professor foi pouco valorizada em relação àquele que tinha formação didática. A utilização de estratégias antigas, que partem de definição e se apoiam sobremaneira no livro didático, foram vistas como negativas. Os mais contrários ao professor com tais características foram os estudantes do GLM, embora essa tendência estivesse presente nos outros dois grupos.

\section{CONSIDERAÇÕES FINAIS}

Iniciamos as considerações finais retomando a questão central de nosso estudo: Quais estratégias de ensino despertam a motivação do estudante na aprendizagem de uma disciplina e como ele percebe a participação do professor nisso? De partida, podemos começar a construir nossa resposta estabelecendo uma analogia entre as teorias que sustentam as relações empresariais (o papel do líder organizacional) com as relações na gestão da sala de aula (o líder educador). Os dados obtidos por meio das respostas dos estudantes pesquisados nos permitem inferir que as teorias comportamentais sobre motivação (HERZBERG, 1968; McGREGOR, 1960) são pertinentes tanto no âmbito organizacional quanto nas relações de sala de aula, professor-estudante.

Sônia FONSECA, Sandra MAGINA 


\section{$e$-Curriculum}

Programa de Pós-Graduação em Educação: Currículo

O professor que tem característica comportamental da "Teoria X" põe ênfase naturalmente nas táticas de controle, nos procedimentos em técnicas que dizem o que as pessoas têm de fazer; suas ações estão centradas nas recompensas e punições. Foi perceptível nas respostas dos estudantes, mesmo que intuitivamente, que esse estilo não promove a motivação. Embora alguém possa supor que tal estratégia, de alguma forma, propicie a aprendizagem, ela não se dá de forma prazerosa e, como bem disseram alguns dos estudantes, tem a duração necessária para "passar de ano".

Já o professor com as características da "Teoria Y", por outro lado, tem uma preocupação com a natureza das relações e procura criar um ambiente que estimule o compromisso com os objetivos da aprendizagem, proporcionando oportunidades para o exercício da iniciativa, da engenhosidade e da autodireção. Esse contexto parece favorecer o surgimento da motivação do estudante, permitindo a maior integração dele com a disciplina. Assim, o professor e a disciplina marcam positivamente o estudante.

O professor que propicia um clima de sala de aula agradável e descontraído permite que o estudante se sinta à vontade para expor as suas dúvidas e avançar na construção de seu conhecimento. A dúvida demonstra que nós ainda estamos pensando; aprendemos quando temos disposição para reexaminar e confrontar novos fatos e evidências contundentes com aqueles que tínhamos baseados em crenças, ou ainda com certo grau de superficialidade. E, assim como nas relações empresariais, é o líder educador que mediará essa interação entre o estudante e o conhecimento.

$\mathrm{O}$ nosso estudo mostrou que o que tem sido dito pela literatura sobre um bom professor (TARDIF, 2008, 2009; NÓVOA, 2002, 2009; MASETTO, 2003; FONSECA, 2007, entre outros) é percebido intuitivamente pelo estudante. É claro que não houve unanimidade, mas sem dúvida, há uma clara tendência dos estudantes dos três grupos em apontar características de boas e de más práticas pedagógicas. Tal observação nos permite defender a ideia de que os estudantes, independentemente de o curso ser ou não humanista, compreendem que ser professor é ir além da burocracia imediatista; é estar comprometido com o processo de aprendizagem de seus estudantes; é ter preocupação e conhecimento para estratégias diferenciadas e eficientes que contribuam para a apropriação dos conceitos; é saber enxergar os estudantes sem, contudo, ser 


\section{e-Curriculum}

Programa de Pós-Graduação em Educação: Currículo

confundido como alguém muito passivo ou egocentrado demais; é, por fim, ser, nas palavras de Masetto (2003), "um profissional professor".

A falta de formação pedagógica para ministrar aulas se mostrou um ponto comum nas queixas dos alunos. Todos reconhecem a necessidade do saber do professor, mas a maioria explicita que isso só não basta para garantir uma boa prática pedagógica.

Assim, concluímos que os estudantes de todos os três cursos, com maior ou menor ênfase, apontaram para a necessidade de o professor rever suas práticas pedagógicas, respeitando o estudante, buscando estratégias que facilitem a aprendizagem, estimulando os questionamentos e as críticas dos aprendizes. Enfim, esses estudantes deixaram claro que é preciso que o professor desperte neles a motivação para aprender por meio da criatividade, da espontaneidade e do respeito. 


\section{REFERÊNCIAS}

AUSUBEL, David. Algumas limitações psicológicas e educacionais da aprendizagem por descoberta. In: NELSON, L. N. O ensino: textos escolhidos. Trad. de Joshuah de Bragança Soares. São Paulo: Saraiva, 1980.

. Aquisição e Retenção de Conhecimentos: Uma Perspectiva Cognitiva. Trad. Lígia Teopisto. Lisboa: Paralelo Editora, 2000.

. Aquisição e Retenção de Conhecimentos: Uma Perspectiva Cognitiva. Trad. Lígia Teopisto. Lisboa: Paralelo Editora, 2003.

FONSECA, Josefa Sônia. A interferência do modelo de gestão no projeto pedagógico de uma instituição de Ensino Superior: Um estudo de caso. Tese de Doutoramento, Pontifícia Universidade Católica de São Paulo. São Paulo, 2007.

HERZBERG, Frederick. One More Time: how do you motive employees? Boston (MA): Harvard Classics Series, 1968.

MASETTO, Marcos Tarciso. Competência Pedagógica do Professor Universitário. São Paulo: Summus, 2003.

McGREGOR, Douglas. The Profissional Manager. New York: McGraw-Hill, 1960

El Lado Humano de las Organizaciones. Madrid: McGraw-Hill, 1994.

MAXWELL, John C. Seja o Líder Que Todos Querem Ter. 1ª ed. São Paulo: Sepal, 2002.

MINICUCCI, Agostinho. Psicologia Aplicada à Administração. 5. ed. São Paulo: Atlas, 1995.

NOVOA, António. Formação de Professores e Trabalho Pedagógico. Lisboa: EDUCA, 2002. . Professores Imagens do Futuro Presente. Lisboa: EDUCA, 2009.

RUDIO, Franz V. Introdução ao Projeto de Pesquisa Científica. Petrópolis: Vozes, 32. ed, 2001.

TARDIF, Maurice. Formação dos Professores e Contextos Sociais. Porto: Rés , 2008.

O Trabalho docente: elementos para uma teoria da docência como profissão de interações humanas. Petrópolis, RJ: Vozes, 2008. 


\section{e-Curriculum}

Programa de Pós-Graduação em Educaçãa: Currículo

Artigo recebido em 04/08/2017.

Aceito para publicação em 07/09/2017. 